\title{
Research on the Path of Smart Campus Construction Facing Data Governance
}

\author{
Bo Liu ${ }^{1,2}$, Zhongwen Zhou ${ }^{3, *}$, Bei Wu ${ }^{4}$, Yi Gong ${ }^{1}$, Juan Yang ${ }^{1}$ \\ ${ }^{1}$ Information Technology Centre, Sichuan Radio and TV University, Chengdu, Sichuan 610073, China \\ 2 Educational Information Management and Information Systems Research Centre, the Open University of China, \\ Beijing, Beijing 10039, China \\ ${ }^{3}$ Institute of Engineering and Technology, Sichuan Radio and TV University, Chengdu, Sichuan 610073, China \\ ${ }^{4}$ Institute of Information Engineering, Sichuan Huaxin Modern Vocational College, Chengdu, Sichuan 610107, China \\ *Corresponding author. Email: liuq8@163.com
}

\begin{abstract}
Smart campus and educational governance are the hot spots of university informatization, and data governance is an important task in the middle and late period of smart campus. In order to solve the problems such as unclear definition and unclear target of smart campus construction, this paper expounds four principles of school data management and four goals of school data management on the basis of combing the present situation and predicament of university information construction. In the implementation path, this paper proposes two kinds of data governance paths: standard model and process-driven, designs the top-level data governance flow chart and user metadata-driven flow chart, and makes the functional positioning from multiple roles such as manager, teacher and student. Finally, this paper discusses the application of data governance path in general higher education and adult education, analyses the advantages and difficulties of the two paths, and provides support for the future application of big data, and its ideas can be used for reference and promotion.
\end{abstract}

Keywords: Data governance, education governance, data analysis, smart campus, big data, wisdom education

\section{INTRODUCTION}

The concept of smart campus had been developed for nearly ten years since its birth, which was the advanced form of university informatization and the further expansion and promotion of digital campus. The emergence and development of cloud computing, Internet of things, mobile Internet, big data analysis and other technologies provide effective technical support for the construction of smart campus, and finally make the realization of smart education. The Technical Standard and Data Specification for the Construction of smart Education in Shaanxi Province had contained 8 specifications on the construction, such as guidance of integrated management platform, the basic data standard of education, the standard of basic code of education. [1]. General Framework of smart Campus (GBT36342-2018) had defined how to deploy the overall structure of intelligence campus, realized the environment of wisdom teaching, deployed the management system of wisdom teaching and constructed the service of wisdom teaching[2].

The smart campus synthetically uses the new information technology, perceives the campus physical environment comprehensively, smartly identifies the learning, work situation and individual characteristics of the group of teachers and students, organically connects the school physical space with the digital space, and establishes an smart and open education and teaching environment and a convenient and comfortable living environment for teachers and students, and realizes the individualized and innovative service of people-oriented [3-5].

At the level of theoretical research, a total of 3000 articles were searched in CNKI by using the keyword "smart campus ". The analysis found that the domestic research on smart campus started in 2010 , which was formed and attracted great attention from the academic circles in 2013. Through the analysis of the literature, it was found that in recent years, there were 23 related national educational science planning projects, 22 national natural science foundation projects and 16 national social science funds, which reflected the high attention of the state to the study of smart campus. Further analysis had shown that the research focus of the above projects was on two aspects: one was the key technology of smart campus; the other was the research of smart campus system model and solution. But the application mode, extension mode and application evaluation of smart campus were not involved much.

Based on the principle of data management and the goal of data governance, this paper expounds the standard data governance model and the process-driven data governance model, compares the two construction paths in many dimensions, and analyses its advantages and difficulties through practical cases. It provides a reasonable path for the mid-term construction of smart campus. 


\section{BACKGROUND}

In the use of smart education platform, the questionnaire is entitled "cloud education platform application in higher vocational colleges ", the main content of which is:" smart education platform refers to the teaching and management platform constructed by using cloud computing, and its foundation is the network education platform, the general name of the software system that provides comprehensive support services for network teaching. A complete support platform based on wisdom teaching should be composed of three systems: the wisdom curriculum development system, the wisdom teaching support system and the wisdom teaching management system, respectively, to complete the functions of network curriculum development, network teaching implementation and network teaching management. In order to understand the application and promotion of wisdom education platform in higher vocational colleges, this questionnaire is specially set up." According to the feedback results of the questionnaire, 200 teachers and students participated in the answer. More than 85 per cent of people agreed to use mobile devices to access education platforms, 66 per cent use social accounts to log on to education platforms, and only 69 per cent focused on learning quality.

\subsection{Present Situation of smart Campus Construction}

In the process of smart campus construction, Sichuan Technology and Business University had made great efforts to promote the construction of smart campus by formulating the 13th Five-Year Plan of smart Campus Informatization, and had explored the road of educational informatization development in private colleges and universities with the integration of information technology and education. Chengdu Normal University combined with the construction practice of "wisdom community" in XX district of Chengdu, expounded the construction principle, path and content system of "wisdom community ". Guided by the principle of unity and platform, Sichuan Vocational College of Information Technology put forward a new structure of smart campus infrastructure, and analyzed and solves the key technical problems [6]. The above research focused on the theoretical practice analysis and neglected the comprehensive innovation in application; there was no construction path of data center, and it was useless to analyze all kinds of data synthetically, so it lacked comprehensive data support.

\subsection{Status Analysis of Data Governance}

In the process of data management, Nanjing City Vocational College put forward the process reengineering mode of smart campus according to the enterprise business reengineering process framework; Renmin University of China integrated the data formed by years of information development through the construction of data sharing center, reorganized the existing data standards and constructs the school sharing database; West China Hospital made medical information management into high quality and high availability data through the platform, and then combined data mining method and sharing technology, realized the efficient utilization of medical data resources; Vanderbilt University adopted a series of data governance strategies, made full use of data value, and provided the basis for scientific decision-making in teaching, management, research, service and medical treatment in schools.

The above research held that the smart campus was a higher form of educational informatization development in universities, and should provide reference for the application development of smart campus from the basic supporting environment, the level of digital educational resources and the level of application ability. But in the process of information technology's deep application to big data, the data forming mechanism and data standard which constituted data sharing need to be built and perfected urgently.

\section{PRINCIPLES AND OBJECTIVES FOR DATA MANAGEMENT}

Under the dual drive of smart data and data service, universities formulated unified data standards, constructed shared data centers, and realized business data fusion. But there were problems such as low data quality, chaotic data flow, insufficient sharing degree, missing historical data. Therefore, the construction of smart campus focused on data management, integrated and integrated all kinds of school business data, realized the unified management of school data, promoted the sharing of school affairs data, and played an important role in the service of teachers and students, teaching management and scientific research.

\subsection{Management Principles of School Affairs Data}

School affairs data is the public resources and important assets of the university, which refers to all kinds of data generated or obtained by all teachers and students in departments of universities using information systems. Four principles should be followed in school affairs data management.

(1) The principle of overall construction.

According to the relevant standards of the Ministry of Education, the relevant data standards of schools are formulated, and the collection, storage, exchange, sharing and application of data are carried out, and the "one data, one source" and "multiple checks" should be adhered to. The university co-ordinated the construction of school 
affairs data catalogue system and the sharing exchange system.

(2) The principle of full sharing

Based on the overall sharing in school, under the premise of ensuring data security, we provide all kinds of information data sharing services, so that the data can meet the needs of various business use and decision support.

(3) The principle of legal use

The school affairs data shall be used legally and reasonably, and shall not be abused. State secrets, school secrets and personal privacy shall not be disclosed, and the legitimate rights and interests of the subject of school affairs data shall be safeguarded.

(4) The principle of safe and controllable

Relying on the school network security system, we improve the school data sharing security mechanism, and ensure the school data security.

\subsection{Governance Objectives of School Affairs Data}

(1) Ensure that school affairs data is complete and accurate We establish the collection mechanism of all the data in the school; avoid the lack of data, multiple collections and repeat collection. We establish the data exchange and quality verification mechanism according to the business requirements and the data quality management standard, and ensure the complete, accurate, true and standardized data of each link.

(2) Ensure that school affairs data is safe and reliable

We establish a hierarchical management and backup, disaster recovery and recovery mechanism of data. We establish a log recording mechanism for data operations to ensure that data changes could be traced back. According to the requirements of the country and schools, we do a good job of data confidentiality.

(3) Ensure that school affairs data is fully shared

We establish the public data platform exchange mechanism, define the data generation department and the use department, and ensure the data to be available in the school each department.

(4) Ensure that school affairs data use specification

We establish the examination and approval of data use, open and other management mechanisms, on the basis of the protection of personal privacy, reasonable use of data to assist management and decision-making.

\section{DATA GOVERNANCE PATH IN INTELLIGENCE CAMPUS}

The initial goal of intelligence campus is to build three basic platforms of unified identity authentication, Single Sign-On and personal portal, which solved the problem of application integration; the medium-term goal is to build data center by using data standard, and the later goal is to provide data application service, which solved the problem of data integration. Therefore, data governance is the core of the construction of smart campus in the middle and late stage, and it is the basis of realizing big data analysis. Data governance is divided into standard mode and processdriven mode according to the implemented path classification.

\subsection{Standard Data Governance Model}

As shown in figure 1, the standard governance model is the overall goal of intelligence campus. It follows the process of application integration, business integration, data integration, data classification, data application. It is a data governance model from whole to part. According to the information system and business process of the school, the shared data platform is divided into functional domains such as human resources, student management, teaching management and scientific research management.

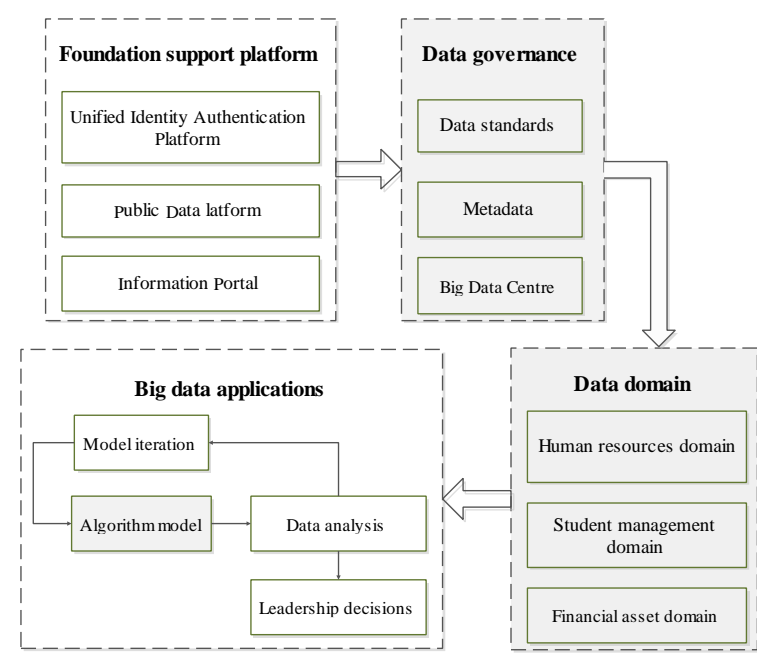

Figure 1 Standard data governance process path

The organizational domain includes organization name, organization nature, organization level, subordinate relation, personnel establishment, cadre establishment and so on. Human resources domain includes basic information of teaching staff, learning experience, post appointment, professional and technical post appointment, teacher qualification information, teacher ethics information, domestic training, overseas study, skills and certificates, contact information and other related data. Student management domain included student number, ID number, name, gender, nationality, political outlook, school, major, admission time, graduation time, status of student status and other related data.

The teaching management domain includes related data such as major, teaching plan, course, teaching process, examination, graduation, teaching team and classroom and so on. The teaching resource domain includes the related metadata such as network courses, video and audio learning resources, multimedia courseware, virtual experiment, text teaching materials, books and documents, etc. The field of scientific research management includes relevant data such as scientific research institutions, 
scientific research projects, scientific research activities, scientific research achievements, scientific research funds and so on. The financial asset domain includes financial management, fund management, bidding management, fixed assets management, intangible assets management, equipment management, real estate management and other related data.

\subsection{Process-driven Data Governance Model}

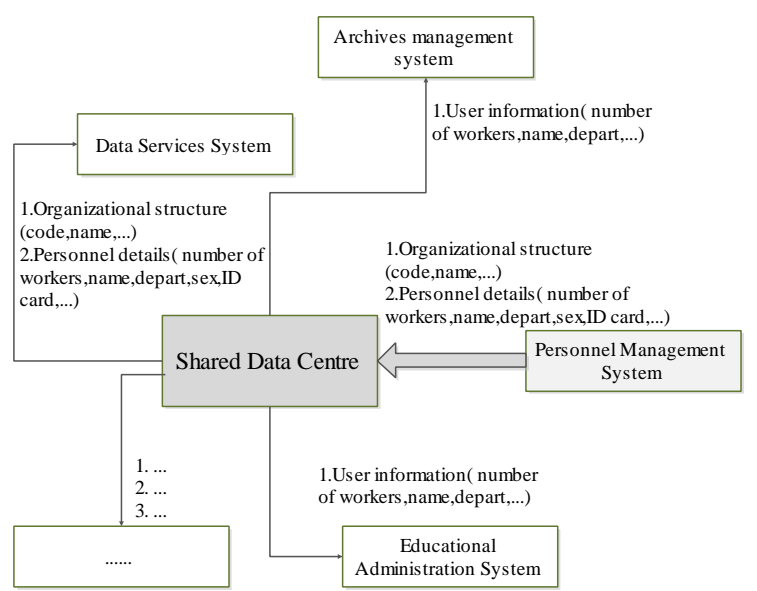

Figure 2 Metadata flow of user information

The essence of process-driven is to form an optimized set of business processes by combing and reengineering various business processes within the school, combining with software tools such as data bus, process engine and rule engine to drive data flow and service customization. The standardization, standardization and automation of vertical and horizontal management lines in the school are realized [8-9].

As shown in Figure 2, the process-driven governance model takes faculty metadata as an example. First, the detailed personnel information is extracted from the personnel management system to the shared data center; then the key personnel information is extracted from the data center according to the requirements of the file management system and the educational administration system; finally, the data service and data display are provided according to the requirements of the data service system. The human information requirements in the figure drive the production, cleaning, encapsulation and application of user information metadata.

\subsection{Selection and Evaluation of Data Governance Path}

For different types of colleges and universities, the construction path of smart campus data governance is different. In the process of smart campus construction of ordinary universities, it has fixed teachers and students and fixed teaching mode, the adjustment range of business process is small, and its data generation and management have the characteristics of clear process. So we choose the standard governance mode to have certain advantages. In the construction of smart campus for adult education universities, the flow of teachers and students is high, the teaching mode change greatly, and its user group, data generation and governance have the characteristics of multi-linear. So it is of practical significance to choose the process-driven mode.

Table 1 Path comparison between two types of data governance

\begin{tabular}{|c|c|c|}
\hline & Standard governance model & Process driven model \\
\hline School administrator & $\begin{array}{l}\text { Carry out top-level design, provide overall } \\
\text { demand, and coordinate later construction } \\
\text { departments. }\end{array}$ & $\begin{array}{l}\text { Entrusting a business department to } \\
\text { provide the process. }\end{array}$ \\
\hline Department & $\begin{array}{l}\text { Provide relevant data, comb the whole } \\
\text { business process, and assist in improvement } \\
\text { and optimization. }\end{array}$ & $\begin{array}{l}\text { Comb individual business processes, } \\
\text { optimize flow charts. }\end{array}$ \\
\hline Teacher & $\begin{array}{l}\text { Provide teaching related process, and } \\
\text { improve teaching data service. }\end{array}$ & $\begin{array}{l}\text { Discovery and optimize individual data } \\
\text { flow services. }\end{array}$ \\
\hline Student & $\begin{array}{l}\text { Discovery intelligence campus data service, } \\
\text { and assist data service optimization }\end{array}$ & $\begin{array}{l}\text { Discovery and optimize individual data } \\
\text { flow services. }\end{array}$ \\
\hline Technician & $\begin{array}{l}\text { Achieve smart management, safety } \\
\text { management, easy to maintain. }\end{array}$ & $\begin{array}{l}\text { Implement the data flow in the business, } \\
\text { and analyze the metadata model. }\end{array}$ \\
\hline
\end{tabular}

As compared with the two data governance models in Table 1, the implementation of the standard governance model is difficult, the construction cycle is long, and the integrity is good; the implementation of the process-driven model is low, the construction cycle is short, and the 
integrity is poor. The school should chose the appropriate data governance model from the different role needs of managers, teachers and students and technicians, and it achieve the purpose of big data application.

\section{CONCLuSion}

In the process of changing the digital campus to the smart campus, data governance is a huge and complex system engineering, which involves many factors, such as personnel organization, program planning and business process. On the basis of literature research and university practice analysis at home and abroad, this paper gives four principles of data management and formulates four objectives of data governance; it focuses on the analysis of standard data governance model and process-driven data governance model. For general higher education and adult education, the two construction paths have their own advantages and disadvantages. The next step is to formulate a number of data indicators and evaluation indicators to improve the practicality of the path.

\section{ACKNOWLEDGMENT}

This work was supported by the Sichuan Radio and Television University Foundation of China (KTKYC2020001Z， XMKYC2020011Z and XMKYC2020014Z), and Natural Science Research Project of Sichuan Education Department (18ZA0317).

\section{REFERENCES}

[1] Education Department of Shanxi Provincial Government. "Technical Standard and Data Standard for the Construction of Wisdom Education in Shaanxi Province" [EB/OL]. http://www.ict.edu.cn/p/shaanxi/tzgg/n201409295386.html . 2014-09-29.

[2] State Administration of market supervision and administration of the people's Republic of China. "General Framework for Smart Campus(GBT36342-2018)" [DB /OL ] . https://www.sohu.com/a/241238400_654086. 2018-07-14.

[3] Ministry of Education of the People's Republic of China. "Modernization of Education in China (2035)" [EB/OL].

http://www.moe.gov.cn/jyb_xwfb/gzdt_gzdt/201902/t2019 0223_370857.html,2019-02-23

[4] LIANG Wei. The Research of the Construction and Application of smart Campus-Interpretation of Standard Guideline for the Construction and Application of smart Campus in Primary and Secondary Schools in Shenzhen (Trial) [J]. Technology in Education, pp.119125,2016

[5] Liu B, Yang Y, Zhou Z. "Research on Hybrid access Control Strategy for Smart Campus platform". Proceedings of 2018 IEEE 3rd Advanced Inoformation Technology, Electronic and Automation (IAEAC), IEEE Press, 2018, pp.342-346. DOI: https://doi.org/10.1109/IAEAC.2018.8577828

[6] Tang Ci, Peng He Junlin. Inquiry and Practice of Wisdom School District [J]. Software Guide, Vol 15, pp.137-139, 2016

[7] Khabou Nesrine, Rodriguez Ismael Bouassida, Gharbi Ghada, Jmaiel Mohamed. A Threshold based Context Change Detection in Prevasive Environments: Application to a smart Campus[J]. Procedia Computer Science, pp.461-468, 2014

[8] Liu Geping, Zhong Jian, Xie Tao. Research and Practice of Process-Driving Based Basic Framework of smart-Campus in Higher Education [J]. China Educational Technology, pp.23-28, 2019

[9] Zhang Shiming, Peng Xuefeng, Huang Hexiao. A Study on the Data Governance Framework of Open Universities [J]. China Educational Technology, pp.116126, 2018 